\title{
Revitalization of urban industrial areas based on sustainable development principles
}

\author{
I. V. Potseshkovskaya, A.N. Soroka \\ Department of Architecture, Faculty of Civil Engineering of St. Petersburg Mining \\ University, Russia
}

\begin{abstract}
The article considers the formation of industrial territories in the structure of a historical city and the need to revitalize them in modern conditions on the basis of an integrated approach. Its goals and main objectives of revitalization are given. The problem of the industrial "belt" of the historical city, in particular, the "Grey Belt" of Saint Petersburg, and the potential of depressed former industrial areas in the structure of the city are shown. Examples of reconstruction and adaptation for the new functions of New Holland Island, the revitalization of a part of the territory of the Sevkabel Port plant into public space, and the Loft Etagi Project in the industrial zone in St. Petersburg are described.
\end{abstract}

\section{Introduction}

The development of scientific and technological progress since the mid-19th century has resulted in mass industrialization and construction of plants and factories in large cities. Industrial enterprises were built near railway transport routes, which usually were the boundaries of the urban territory of the 19th and 20th centuries. Geographically developing in the 20th century, the historical cities preserved the industrial development of the 19th century in their central parts. Some of the industrial facilities were erected in the first half of the 20th century [1]. The gradual development of urban infrastructure has resulted in a large number of industrial areas in the city, which are currently partially closed. This led to the deterioration of living conditions: unsanitary conditions and slums emerged, and social and economic conditions deteriorated. This problem was solved by the settling part of the population and landscaping. After the end of World War II, there was a need to rebuild destroyed cities and develop new master plans for them. 


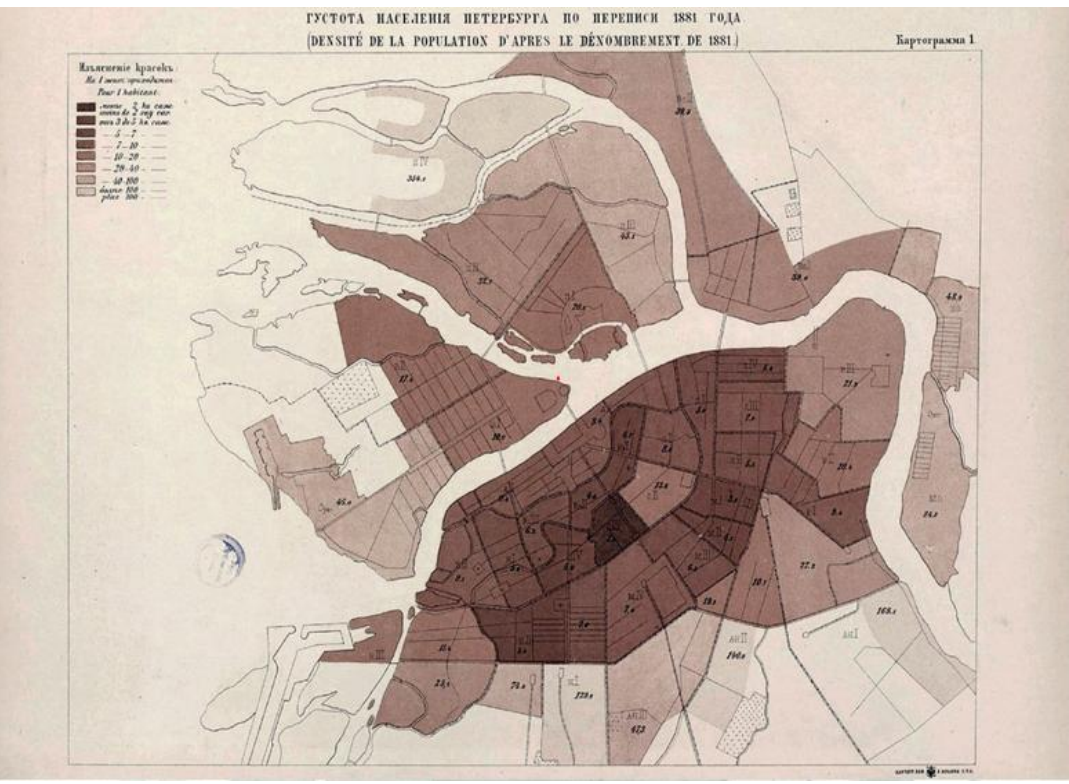

Fig. 1. Territorial boundaries of St. Petersburg and population density (1881).

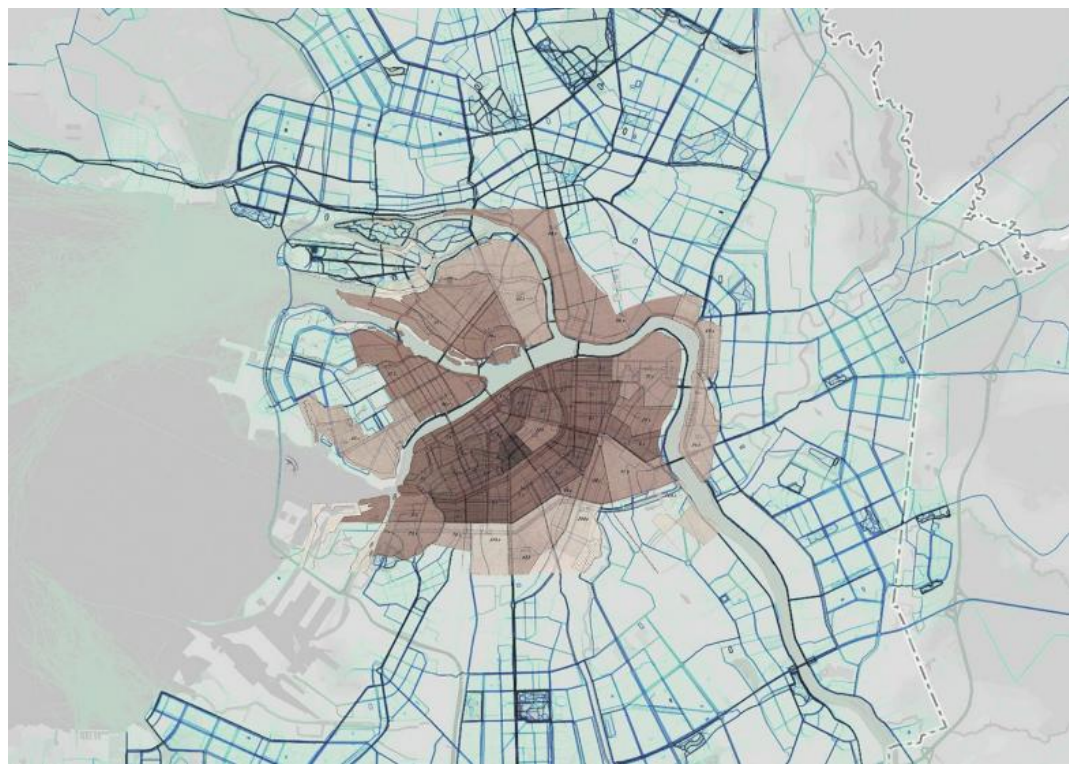

Fig. 2. St. Petersburg transport network diagram (present time).

However, they aimed at solving priority tasks: reconstruction of residential development, infrastructure, and transport communications. Thus, in the second half of the 20th century, the problem of bringing industrial enterprises out of the city and adapting historical industrial buildings (which in most cases became objects of cultural heritage), which have lost their functional importance, became more relevant [2]. Extensive reconstruction and adaptation to the new function of individual historic buildings have failed to successfully transform the urban environment in the former industrial zones. 


\section{Results and discussion}

The renovation of industrial areas is an important problem of modern megacities. New approaches are being developed to address this problem [3], the most relevant of which is revitalization. In the context of urbanization, revitalization refers to the adaptive use of territories, buildings, structures, and complexes when changing their functional purpose and further use. The main objectives of the revitalization of the former industrial areas are:

- Giving new functions to territories with historical development and creating a comfortable urban environment, while the renewed territory should become a new point of attraction on the scale of the city - for regular and periodic users [4];

- Taking into account the principles of sustainable development, coexistence of natural and artificial environment, and ensuring ecological safety of the habitat [5];

- Attracting investors and increasing economic initiative to improve the quality of life of the population;

- Exploitation in interaction with each other of all vital structural elements of the city territory in the necessary volumes, which is accompanied by the creation of new jobs;

- Providing revitalized territories with as many opportunities as possible for selfrealization and cultural enrichment of society, introduction and consolidation of new scenarios of cultural and leisure activities of citizens, development of educational practices [6];

- Preservation of local identity and sense of belonging to the place $[7,8]$.

The process of revitalization requires an integrated approach that takes into account the preservation of the authenticity of the urban environment and an interdisciplinary approach [9]. The profitability of the renovation of the industrial zone is justified by economic, historical, environmental, and aesthetic characteristics [3]. The basic principle of the revitalization as a complex process of reorganization and renaissance of the urban environment is to reveal new opportunities of old areas and buildings.

Major advantages of the former urban industrial areas include:

- Advantageous location between the historical center and peripheral residential areas;

- Areas of significance;

- Transport availability;

- Developed communication system [10];

- Cultural identity;

- Potential for economic and social development [11];

- Possibility of complex development.

In the process of working on the transformation of former industrial areas, urban planners and architects are conducting detailed research [12]. In reorganizing a part of an urban area, it is necessary to take into account the views of the residents, especially those living in relative proximity to the former industrial buildings. The facility to be designed is part of a township that cannot function separately from the rest of the city structures. 


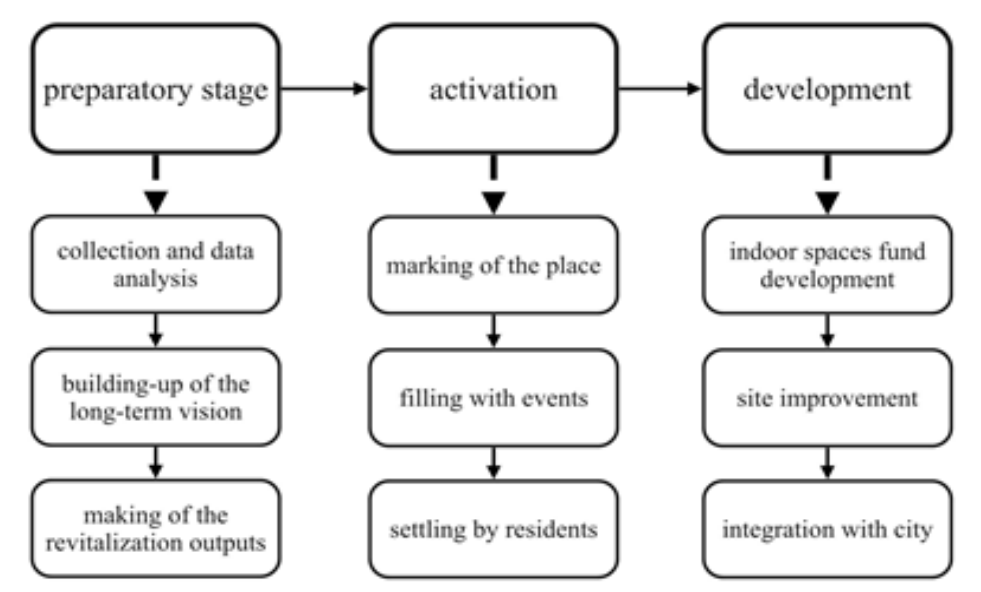

Fig. 3. Revitalization process algorithm.

As the world practice of revitalization of industrial areas shows, legislative support for such processes is essential. For example, the United States has special legislation, organizations and funds governing the redevelopment. The United Kingdom has adopted a national strategy to revitalize industrial areas. In European cities, progress in the reorganization of former industrial zones is based on European legislation and the European Charter for Sustainable Development.

According to Nikita Yavein, the head of the architectural bureau "Studio 44", a large design company in the North-West Federal District implementing its projects in the Russian Federation and abroad, "In Europe, industrial buildings are viewed not as architectural monuments of architecture, but as a memory of a place that cannot be destroyed, but from which one can work. We have two options left: either a complete restructuring with the preservation of individual fragments 'from memory,' or a purely restoration approach" [13].

Coastal depressive industrial zones occupy a special place among the potential areas for new functioning. In major historical cities, a large percentage of the areas near the water (transport arteries) are industrial buildings. The deindustrialization of such territories, the withdrawal of industrial enterprises outside the residential zones will free up large areas for further regeneration, filling them with public spaces and social infrastructure, and the organization of access to water for citizens. Revitalization projects allow to create or transform water "facades" of cities, to improve ecology through the creation of park green zones.

In modern conditions, the revitalization of existing industrial complexes located in the residential zone is very popular, though it is connected with contradictions between the needs of society and the established structure of the urban environment. In such cases revitalization is considered as reconstruction of objects of industrial architecture with the change of their functional purpose.

The problem of unused industrial areas in St. Petersburg is represented by the so-called "Grey Belt". This is a conditional area of historical buildings, allocated by urban planners, industrial facilities, "enveloping " the central part of the city. In the first half of the $2010 \mathrm{~s}$, industrial areas in St. Petersburg occupied $13.6 \%$ of the total area of the city or 19,000 hectares. $2 / 3$ of these are empty and abandoned, depressed areas.

In June 2013, the Committee on Urban Planning and Architecture of St. Petersburg held a joint seminar with the United Nations Human Settlements Organization (UN-Habitat) on the theme of "Reorganization of urban industrial areas: world experience and prospects of 
St. Petersburg". According to the interregional adviser of the UN-Habitat Programme Paulius Kulikauskas, successful renovation of industrial areas requires an integrated and thematic approach based on the principles of sustainable development and contributing to improving the quality of the urban environment and the lives of citizens [14].
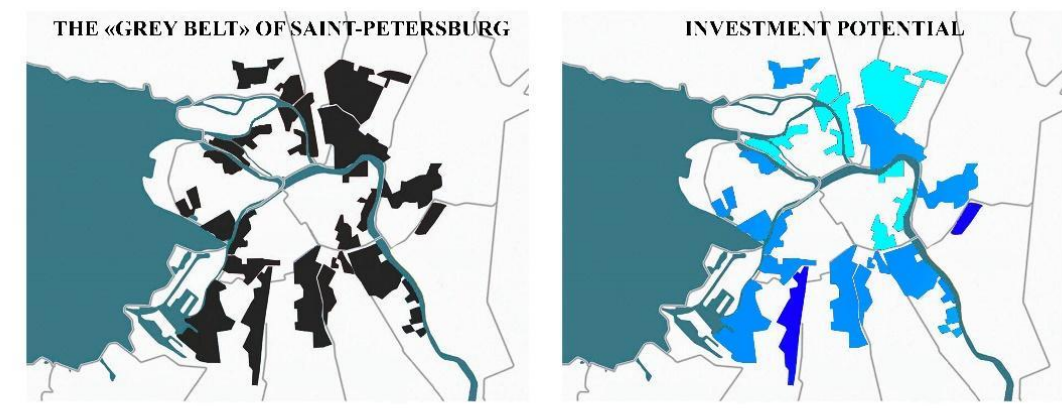

HIGH

MEDIUM

LOW
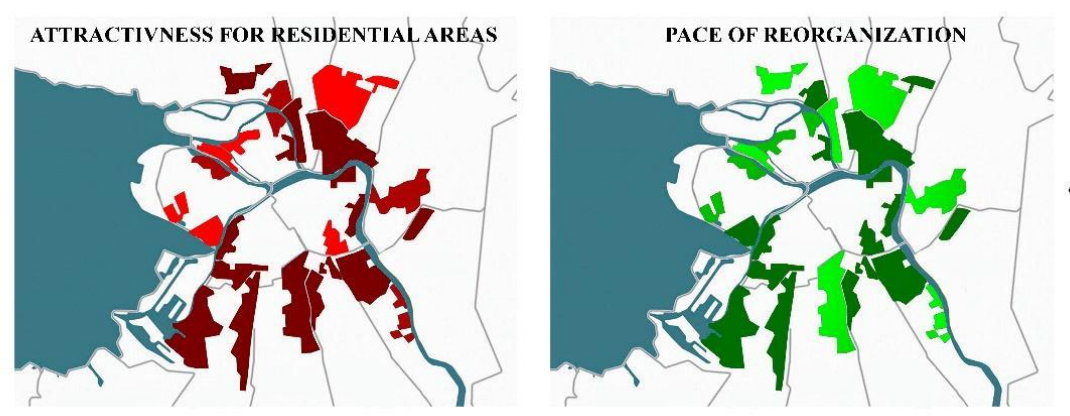

AREA OF POTENTIAL

4200

THIS IS

$4 \%$

OF THE TOTALAREA

Fig. 4. Analysis of potential industrial territories.

In 2016, a restricted international redevelopment competition was held, during which it was necessary to develop a strategy for the development of St. Petersburg, in particular, of the "Grey Belt" [15]. The terms of the competition stipulated that $30 \%$ of the territory should be recreational green areas, 30\% should be commercial and industrial, and $40 \%$ should be residential. Nine teams of architects from St. Petersburg, Moscow, and Europe (Germany, The Netherlands, Norway, and Finland) received one of three sections of the "Grey Belt": the so-called-"French Harbor" (the name came from the name of an artificial body of water created in the 1840s for anchorage of ships), limited by the water area of the Neva and the Obvodnoy Canal; "Volkovskaya" at the eastern side of Ligovsky Avenue; and "Ekateringof" near the metro station "Narvskaya". The work of a consortium of three workshops "Evgeny Gerasimov and Partners" (St. Petersburg), SPEECH (Moscow) and NPC Tchoban Voss (Berlin) was recognized as the best project for the transformation of the territory of the "French Harbor"; the best design project for the "Volkovskaya" area belonged to the Dutch architectural bureau of MLA; the best concept of "Ekateringof" transformation belonged to "Rozhdestvenka" bureau (Moscow) [2]. 


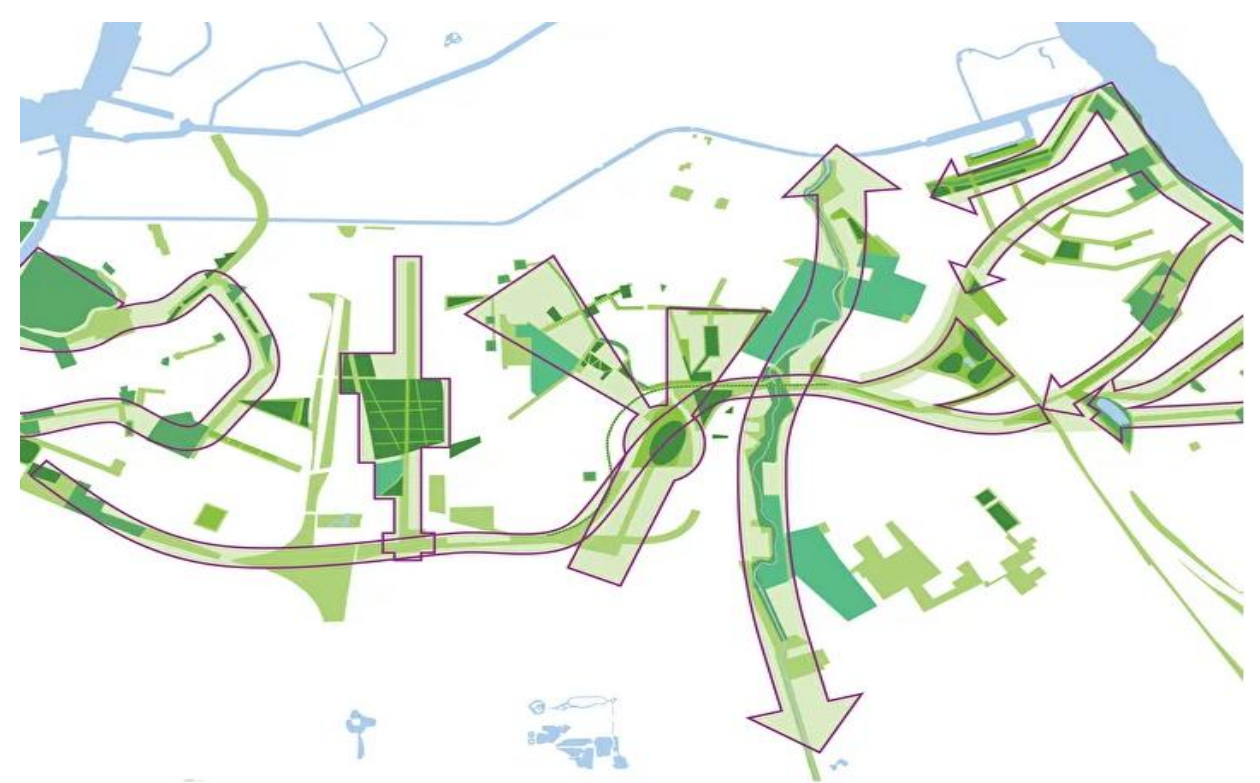

Fig. 5. Concept of "Grey Belt" development. Scheme of a "green" framework. MLA+.

For example, the MLA architectural bureau presented the most detailed functional planning scheme with the concept of integrating modern development into the central areas [15]. The design provided for the combination of reconstruction of industrial buildings and the placement of new types of housing and public spaces.

The New Holland is an example of successful renovation of the city territory and reconstruction of industrial facilities with the adaptation for new functions. These are two artificial islands in the center of St. Petersburg, between the Moyka River, Admiralty and Krukov Canal. Since the time of Peter I, wood was stored here for the construction of ships. Stone buildings on the islands began to be built in the mid-1760s (architects Savva Chevakinsky, Jean-Baptiste-Michel Wallen-Delamot), the arch was erected in $1779-1787$ (architect Jean-Baptiste-Michel Wallen-Delamot). The building of the ring-shaped marine prison was built in $1828-1829$ (architect Alexander Staubert), and the forge building was erected in 1852. The emergence of new buildings dates back to the second half of the 19th century. Ensemble development of New Holland Island suffered from fire in the beginning of the 20th century, artillery shelling during the Great Patriotic War; it was restored and fell into decline again by the end of the 20th century, and in 2004, there occurred a new fire. In 1977, architect Benjamin Fabritski and Galina Kovaleva put forward the idea of transforming New Holland Island into a center of culture and cooperation. Since 2001, the "New Holland" Ensemble has been an object of cultural heritage of federal importance.

The ideas of the last third of the 20th century were continued, and in 2006, the work of the Norman Foster architectural bureau (Great Britain) won the international competition for the project for the reconstruction of New Holland Island. The project recognized as the best provided for the creation of trading and business spaces on the island, the construction of a public and business complex with the Palace of Festivals. In the center of the island, a 3000 -seat amphitheater covered with a glass dome was planned. The project was based on the temporary regulations for the development of St. Petersburg. The General Directorate of the State Expertise several times returned it for revisions, as the underground construction provided for in the project did not comply with the Federal Law "On Objects of Cultural Heritage (Monuments of History and Culture) of the Peoples of the Russian Federation". 
Due to financial $=$ difficulties, in 2010 , the city authorities officially rejected Sir Norman Foster's project.

In 2010, the second international architectural competition for the development concept of the island of "New Holland" was announced. The short list included four architectural offices: "Studio 44" (Russian Federation), David Chipperfield Architects (United Kingdom/Germany), MVRDV The Netherlands) and WorkAC (USA). The aim of the project was to create a multifunctional cultural and commercial complex, including hotel and entertainment sectors, and retail facilities. Among the tasks addressed were:

- Preservation of the architectural heritage of the island;

- Developing a program for the progress of the role of the island in the urban environment with the account of the existing cultural infrastructure of St. Petersburg;

- Orientation to different target audiences;

- Use of the island's water environment;

- The distribution of transport and pedestrian logistics, interconnection of city and island.

The architectural bureau of WorkAC (USA) won the competition. According to the WorkAC, on the 7.6 hectare island, it was planned to open cultural centers, theatres, museums and exhibition halls, educational institutions and scientific laboratories, as well as offices, residences, and hotels.

In 2011, the island was opened to visitors. In 2014, based on the WorkAC master plan, West 8 (The Netherlands), a company specializing in landscape design, developed a project to reorganize the territory. In August 2016, the implementation of the first stage of the project began. Improvement of the park space, which became available for citizens and tourists, was carried out. Under the coordination of the Committee for State Control, Use and Protection of Historical and Cultural Monuments, some buildings have been renovated. A utility system has been developed. A temporary pavilion for cultural events and catering areas appeared. Children's playgrounds were arranged, a grass lawn was created near the building of the former forge.

The new concept of the island development includes:

- Organization, improvement and gardening of the park;

- Restoration and adaptation to modern use of the former buildings of the forge, prison, commandant's house, and timber warehouses;

- Restoration and improvement of the embankment of the Admiralty Canal and the inner water area of the island, so-called "Harbor";

- Laying of island engineering networks;

- Works on the architectural illumination of the renovated buildings and the park.

Full reconstruction of the island is planned to be completed by 2025 .

The revitalization of the coastal industrial zones of St. Petersburg is one of the pressing problems of the city. At the beginning of the 21 st century, these "iconic" places, as a rule, were not prepared for development, which disrupted the overall view of the city's "sea" façade. Renovation of these territories, taking into account the existing world experience of modern architectural practice, will contribute to the development of sea and yacht tourism. St. Petersburg is a city with a large number of embankments, but all of them have a transport function [16]. There are practically no sections of urban territory with open public spaces facing the water, with places for rest and cultural and mass events, and some special panoramas have been destroyed. In the quantitative ratio of residential development to industrial enterprises, the issue of renovation on Vasilevsky Island is the most acute, as it has a great potential for promising development of coastal territories. However, this provides for the moving of highways underground, which is difficult in the conditions of St. Petersburg soil. At present, construction is actively underway on Vasilevsky Island, both in the central part and in wetlands [17-19]. 
In St. Petersburg, one of the first projects implemented to revitalize an industrial zone was the Port of Sevkabel on the territory of the Northern Cable Plant, founded in 1879 (prerevolutionary name - Siemens \& Halske). Thanks to the activities of the plant specializing in the production of cables and electrical equipment, the first electric trams appeared in St. Petersburg and an electric lighting system of Nevsky Prospect and the Winter Palace was created. After the October Revolution of 1917, the territory of the plant expanded significantly, and some buildings were demolished or rebuilt. After the modernization of the enterprise in the $2010 \mathrm{~s}$, a part of the vacated area of 3 hectares, the management of the plant decided to give to the organization a space with social and business functions. The company Miles \& Yards and the Khvoya Architectural Bureau (Russian Federation) were involved in the project. During a year, the shops were gradually moved to other areas, and reconstruction in the vacated buildings began. The main tasks of architects and developers were to create a "point of attraction" for visitors in the coastal part in the south-west of Vasilevsky Island and to organize an accessible exit to the Gulf of Finland.

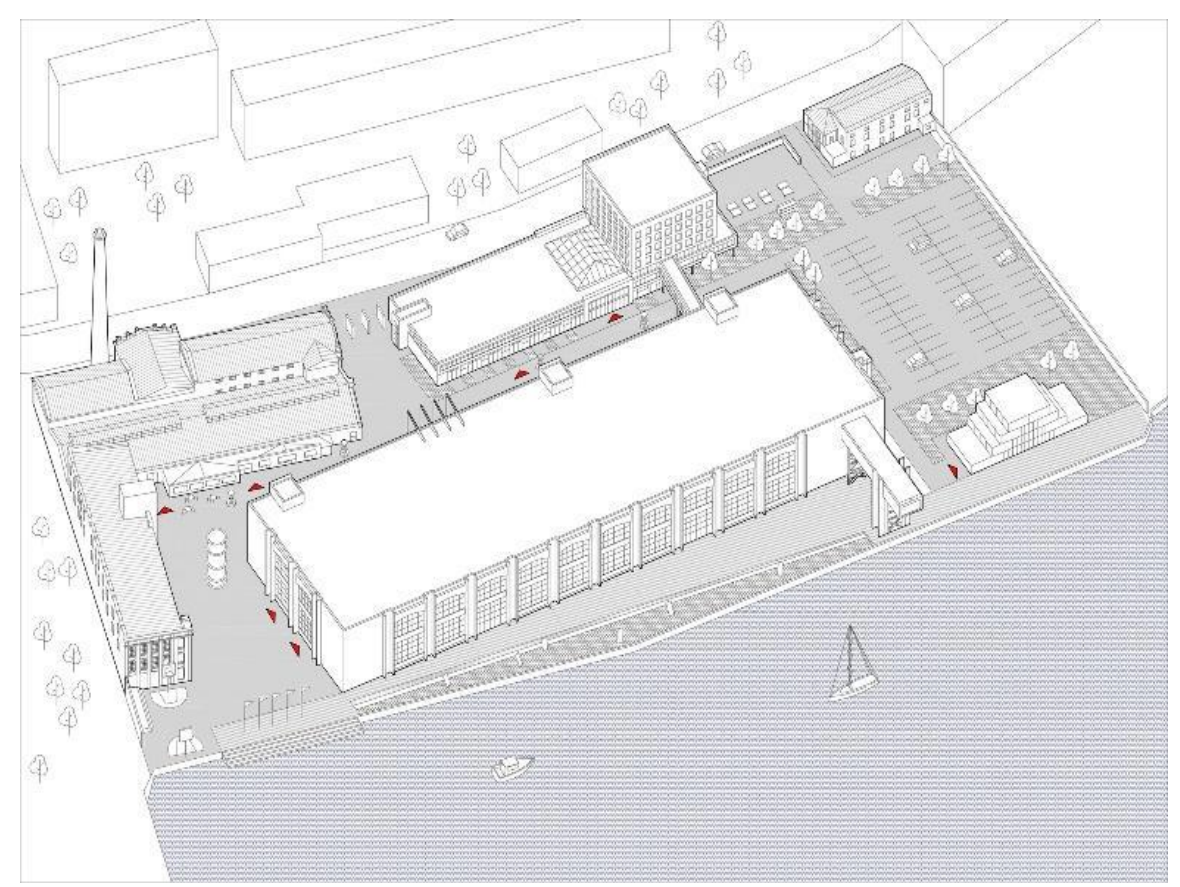

Fig. 6. Sevkabel Port. View from the Gulf of Finland.

The aim of the long-term development is to create a comfortable urban environment and improve the quality of life of citizens living on the territory of the historical Harbour of Vasilevsky Island. The first space was an event platform designed to hold exhibitions, lectures, concerts, and festivals, housed in a historic building where wooden coils for cables used to be produced. A food court with various art objects is located nearby. The main achievement of the project is the organization along the coastline of a section of the section of the embankment with a green lawn and places for recreation, from where a panoramic view of the Gulf of Finland, the Western high-speed diameter bridge across the Ship Fairway, the development of the Canoner Island, the shipyard and the nearby Marine Station opens. on The renovation works on this territory are ongoing. 


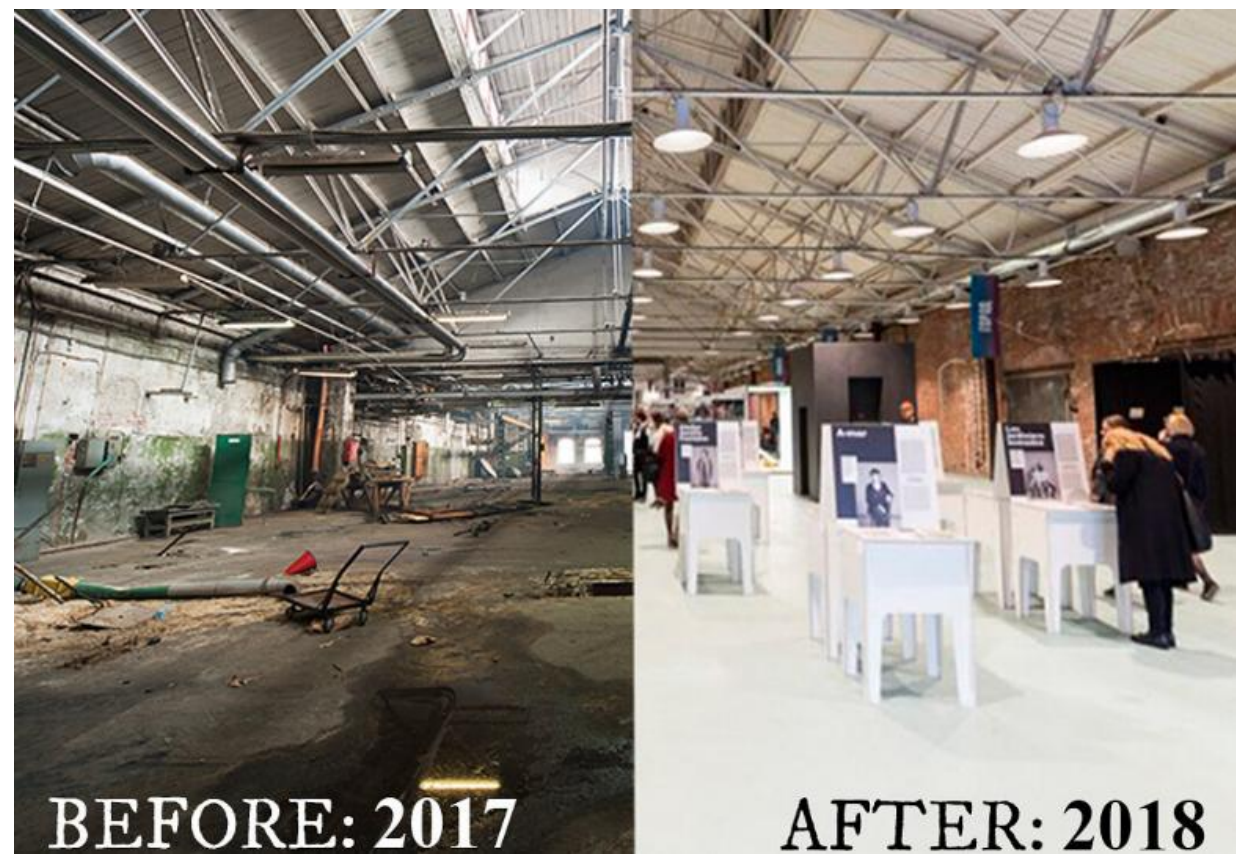

Fig. 7. One of the buildings of the Port of Sevkabel before and after the redevelopment.

A successful example of reconstruction of industrial buildings is the Loft-project Etagi on the territory of the former confectionery production of the Smollninsky Bakery Plant, built between 1936 and 1938. JKMM Architects (Finland) won in the restricted competition organized by the Project Baltia, magazine. The architects linked new objects and existing production buildings in a checkerboard pattern, alternating the emptiness of conventional sections. In 2007, the former industrial territory was transformed into a creative zone [14]. The five-storey building, which houses the office and exhibition center of the Smollninsky Bakery Plant, has halls for exhibitions, office premises, and a gallery of modern art.

It is important to emphasize that while there is an interesting concept in each of the above three examples of reconstruction and adaptation for new functions of production facilities, only the first one fully meets the high aesthetic characteristics. This is a consequence of the economic component in the implementation of project solutions [20].

St. Petersburg needs a comprehensive program to remove production enterprises from the historical center, revitalize former industrial zones and preserve historical buildings on their territory with the possibility of giving them new functions [2]. The "Grey Belt" does not correspond to the economic, social, environmental or urban planning conditions of the city. The city requires its own approach in solving this problem within the framework of the master plan, taking into account the functional zoning of territories. Special responsibility is imposed by the status of the historical center of St. Petersburg and its associated group of monuments as a UNESCO World Heritage Site. 


\section{Conclusions}

In conclusion it should be noted that revitalization is a complex process and a relatively new method of designing functional zones in the city, which should become popular centers of attraction for public life. Such projects require special attention and, as explained at the beginning, an integrated approach due to the need to manage a large number of urban structures and significant financial investments [21]. The right solution may be to gradually transform urban spaces through phased revitalization of smaller areas. A competent redevelopment strategy taking into account international experience is required to form a model that can become a model for other cities of the Russian Federation.

\section{References}

1. M.S. Stieglitz Industrial Architecture of Saint-Petersburg of 18 - first half 20 centuries, Historical and Cultural problems :dis. ... d-r architecture. (I. E. Repin SaintPetersburg state academic institute of painting, sculpture and architecture of Russian Academy of Arts, Saint-Petersburg, 2002).

2. International forum "Industrial revolution", Architectural Petersburg (2012).

3. M.V. Volkodaeva, O.A. Taranina, Y.A., Volodina, V.A. Kuznetsov Development of industrial environmental control methods, IOP Conference Series: Earth and Environmental Science, 378(1), 012108 (2019).

4. M.V. Volkodaeva, O.A. Taranina, Y.A. Volodina Functional zoning of urban areas with regard to environmental quality is one of ways to create more favourable conditions for life, IOP Conference Series: Materials Science and Engineering. 687(6), 066041 (2019).

5. M.A. Pashkevich, J. Bech, Biogeochemical assessment of soils and plants in industrial, residential and recreational areas of Saint Petersburg, Journal of Mining Institute, 241(1), 125-130 (2020).

6. A. Christopher, S. Ishikawa, M. Silverstein, M. Jacobson, I. Fiksdahl-King, S. Angel A Pattern Language: Towns, Buildings, Construction (Center for Environmental Structure Series). (New York: Oxford University Press, 1977).

7. C. Grodach, R. Ehrenfeucht Urban Revitalization: Remaking cities in a changing world. (New York, Oxon: Routledge, 2015).

8. L. Krier The Architecture of Community Washington. (Island Press, 2009).

9. S.G. Sheina, A.S. Starodubceva Sustainable development of cities. Complex process of urban transformation, Engineer newsletter of Don, 2, (2017).

10. Kornienko, S. V. Revitalization of Industrial Zones: Search for Systematic Renewal of a City. Energy saving, 6: 14-19. (2019).

11. M.E. Skachkova, O.J. Lepikhina Methods of standard rates of financial expenses calculation on landscaped areas maintenance (On the example of St. Petersburg, Russia), International Journal of Economics and Financial Issues, 6(4), 1851-1857 (2016).

12. B. Podhalański Ecology as an icon of the contemporary development of metropoleis. International Multidisciplinary Scientific Geo Conference Surveying Geology and Mining Ecology Management, SGEM, 17(63), 845-852 (2017).

13. Factory quality of the Russian province. Architectural Petersburg, 0: 11. (2010).

14. Architecture for street-art, Architectural Petersburg, 23-24 (2013). 
15. Architects shared the "Grey Belt". Architectural Petersburg, 40, 2-3 (2016).

16. I. Dyachkova, M. Skachkova, V. Kovyazin The influence of transport vibrations on the condition of a Russian cultural heritage object, IOP Conference Series: Materials Science and Engineering, 817(1), 012009 (2020).

17. A.G. Protosenya, M.O. Lebedev, M.A. Karasev, N.A. Belyakov Geomechanics of lowsubsidence construction during the development of underground space in Large cities and megalopolises, Journal of mechanical and Production Engineering Research and Development, 5(9), 1005-1014 (2019).

18. A.A. Shubin, P.K. Tulin, I.V. Potseshkovskaya Research on the Effect of the Concrete Reinforcement Structure in the Stress-Strain State of Structures, International Journal of Applied Engineering Research, 12, 1742-1751 (2017).

19. A. Ushakova Development of Underground Space as Transportation Problem Solution in St. Petersburg, Procedia Engineering, 165, 166-174 (2016).

20. E.B. Baksha Perspective opportunities of revitalizing industrial zones in large cities of Belarus, Newsletter of Brest State Technical University, 1, 24-27 (2012).

21. O.M. Lenkovets Housing renovation in Russia and engineering and environmental aspects of renovation programs, Journal of Advanced Research in Dynamical and Control Systems, 12(4), 1060-1068. 